\title{
Nitrate contamination in drinking water and colorectal cancer: Exposure assessment and estimated health burden in New Zealand
}

\author{
Jayne Richards ${ }^{a}$, Tim Chambers ${ }^{b},{ }^{*}$, Simon Hales $^{\mathrm{b}}$, Mike Joy ${ }^{\mathrm{c}}$, Tanja Radu ${ }^{\mathrm{a}}$, \\ Alistair Woodward ${ }^{\mathrm{d}}$, Alistair Humphrey ${ }^{\mathrm{e}}$, Edward Randal ${ }^{\mathrm{b}}$, Michael G. Baker ${ }^{\mathrm{b}}$

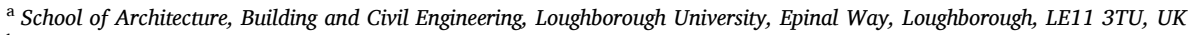 \\ ${ }^{\mathrm{b}}$ Health, Environment \& Infection Research Unit, Department of Public Health, University of Otago, Wellington, New Zealand \\ ${ }^{\mathrm{c}}$ School of Government, Victoria University of Wellington, New Zealand \\ ${ }^{\mathrm{d}}$ Epidemiology \& Biostatistics, School of Population Health, University of Auckland, New Zealand \\ ${ }^{\mathrm{e}}$ Public Health Physician, Christchurch, New Zealand
}

\section{A R T I C L E I N F O}

\section{Keywords:}

Cancer

Water

Nitrates

Exposure assessment

Population attributable fraction

\begin{abstract}
A B S T R A C T
Background: Epidemiological evidence in multiple jurisdictions has shown an association between nitrate exposure in drinking water and an increased risk of colorectal cancer (CRC).

Objective: We aimed to review the extent of nitrate contamination in New Zealand drinking water and estimate the health and financial burden of nitrate-attributable CRC.

Methods: We collated data on nitrate concentrations in drinking water for an estimated 85\% of the New Zealand population $(\sim 4$ million people) who were on registered supplies. We estimated nitrate levels for the remaining population ( $\sim 600,000$ people) based on samples from 371 unregistered (private) supplies. We used the effective rate ratio from previous epidemiological studies to estimate CRC cases and deaths attributable to nitrate in drinking water.

Results: Three-quarters of New Zealanders are on water supplies with less than $1 \mathrm{mg} / \mathrm{L} \mathrm{NO}_{3}-\mathrm{N}$. The population weighted average for nitrate exposure for people on registered supplies was $0.49 \mathrm{mg} / \mathrm{L} \mathrm{NO}_{3}-\mathrm{N}$ with $1.91 \%(95 \%$ CI $0.49,3.30)$ of CRC cases attributable to nitrates. This correlates to 49.7 cases per year $(95 \%$ CI $14.9,101.5)$ at a cost of 21.3 million USD (95\% 6.4, 43.5 million USD). When combining registered and unregistered supplies, we estimated $3.26 \%(95 \% \mathrm{CI} 0.84,5.57)$ of CRC cases were attributable to nitrates, resulting in 100 cases ( $95 \% \mathrm{CI}$ $25.7,171.3)$ and 41 deaths (95\%CI 10.5, 69.7) at a cost of 43.2 million USD (95\%CI 10.9, 73.4).

Conclusion: A substantial minority of New Zealanders are exposed to high or unknown levels of nitrates in their drinking water. Given the international epidemiological studies showing an association between cancer and nitrate ingestion from drinking water, this exposure may cause an important burden of preventable CRC cases, deaths, and economic costs. We consider there is sufficient evidence to justify a review of drinking water standards. Protecting public health adds to the strong environmental arguments to improve water management in New Zealand.
\end{abstract}

\section{Introduction}

Colorectal cancer (CRC) contributes almost $10 \%$ of global cancer incidence (Favoriti et al., 2016). There are major geographic variations in CRC burden worldwide, with high-income countries such as New Zealand (NZ) experiencing markedly higher CRC rates (35.3 age-standardised cases per 100,000) compared with low and middle-income (Bangladesh 3.8 cases per 100,000) (Bray et al., 2018). Māori (NZ's Indigenous population) experience lower rates of CRC than non-Māori, although this gap is reducing over time. Further, while experiencing fewer CRC registrations than non-Māori, Māori are more likely to die from CRC (Blakely et al., 2015).

An estimated $90 \%$ of CRCs are sporadic (non-hereditary), meaning they develop after birth due to a range of modifiable risk factors (Purcell

; CRC, Colorectal Cancer; $\mathrm{NO}_{3}-\mathrm{N}$, Nitrate-Nitrogen: the amount of nitrogen that is in the nitrate ion; NZ, New Zealand; NOC, N-nitroso compounds; MoH, Ministry of Health; DHB, District Health Board; ESR, Environmental Science and Research; PAF, population attributable fraction.

* Corresponding author. 23a Mein Street, Newtown, Wellington, 6023, New Zealand.

E-mail address: tim.chambers@otago.ac.nz (T. Chambers). 
et al., 2017). Common risk factors for CRC include obesity, alcohol consumption, physical inactivity, smoking, and red and processed meat consumption (Bray et al., 2018). Emerging epidemiological evidence has shown that high nitrate concentrations in drinking water may also be a risk factor for CRC (Temkin et al., 2019; Ward et al., 2018).

An International Agency for Research on Cancer (IARC) assessment of studies up to 2006 reported that ingested nitrate under conditions that result in endogenous nitrosation is probably carcinogenic to humans (International Agency for Research on Cancer, 2010). Endogenous nitrosation is a process that involves the reactions between nitrosation agents (metabolised from nitrate) and nitrosatable compounds (eg amines or haeme) to form N-nitroso compounds (NOC). These NOC induce DNA-damaging metabolites, which could lead to cancerous lesions in cells (Gurjao et al., 2021; Zhu et al., 2014). Vitamin C is a known inhibitor of nitrosation so vegetables are a key moderator in this pathway. The role of Vitamin C may explain why vegetable consumption has a protective effect against CRC despite the majority of ingested nitrate coming from vegetables (Johnson et al., 2013). In contrast, water does not contain any NOC inhibiting features. A randomised-controlled trial with human participants showed water-based nitrate increased bio-makers of NOC formation in faeces (van Breda et al., 2019), which supports human feeding studies focusing on dietary nitrate consumption (Hughes et al., 2001; Rowland et al., 1991).

International guidelines for nitrate in drinking water are designed to prevent the acute risk of infantile methemoglobinemia, rather than the chronic risk of cancer (World Health Organization, 2017). Thus, the current WHO drinking water guidelines and NZ drinking water standards for nitrate are $11.3 \mathrm{mg} / \mathrm{L}$ nitrate-nitrogen $\left(\mathrm{NO}_{3}-\mathrm{N}\right.$ - referred to from here on simply as $\mathrm{mg} / \mathrm{L}$ ). However, subsequent well-designed studies have reported associations between nitrate contamination in drinking water and CRC (Espejo-Herrera et al., 2016; Schullehner et al., 2018; Ward et al., 2018).

Nitrate contamination of drinking water can come from agricultural activities, sanitation and from industrial processes (Almasri, 2007). The largest source of nitrate contamination in NZ waterways is from pastoral farming, specifically from intensive dairy farming (Morgenstern and Daughney, 2012). Nitrate leaching from urine patches is the largest source of nitrate contamination from pastoral farming (Parliamentary Commissioner for the Environment, 2013). There is relatively little nitrate leaching from fertilizer application unless the fertilizer application is poorly timed, such as a few days before a high rainfall event (Vogeler et al., 2015). Pre-agricultural, background nitrate levels in groundwater in NZ are estimated to have been $0.16 \pm 0.08 \mathrm{mg} / \mathrm{L}$ (Morgenstern and Daughney, 2012). The latest survey of groundwater sites, but not necessarily drinking water, $(\mathrm{n}=342)$ in NZ found $34 \%$ had concentrations above $3 \mathrm{mg} / \mathrm{L}$ (Ministry for the Environment \& Stats NZ 2019) However, in NZ, no comprehensive national database for drinking water nitrate contamination exists.

Drinking water quality in NZ is regulated under the Health (Drinking Water) Amendment Act 2007 (2019) by the Ministry of Health (MoH). This Act requires suppliers of drinking water to more than 25 people to be included on the Register of NZ Drinking Water Suppliers. In 2020, there were 677 registered drinking water suppliers, serving approximately 4,095,200 people (ESR, 2020) or $\sim 87 \%$ of the 2018 population (Statistics New Zealand, 2020). About $13 \%$ of the population $(\sim 603,500$ people) (ESR, 2020) is not served by a registered drinking water supplier (Statistics New Zealand, 2020). These people are likely to be served by either very small networked supplies or are classified as self-supplied. For the purposes of our analyses we call these 'unregistered supplies.'

In New Zealand. the 'Priority 2 Chemical Determinand Identification Programme ran between 1995 and 2004 (ESR, 2019). If a determinand was found to be less than $50 \%$ of the Maximum Acceptable Value (MAV) ongoing monitoring was not deemed to be required, meaning any water supply reporting less than $5.7 \mathrm{mg} / \mathrm{L}$ was not required to conduct ongoing testing. As a result, in 2019 , nitrate monitoring was only required on supplies that serviced 53,900 people or $1.1 \%$ of the NZ population
(Ministry of Health, 2020).

The burden of CRC attributable to nitrate contaminated water has not been estimated in NZ. Temkin et al. (2019) estimated between one and eight percent of CRC cases in the US could be attributable to nitrate contamination in drinking water. A NZ study has estimated the CRC rates attributable to other known risk factors such as obesity (9\%), alcohol (7\%), physical inactivity (4\%), smoking (3\%), consumption of red meat (5\%) and processed meat (3\%) (Richardson et al., 2016). These estimates represent the population attributable fractions (PAF), the proportion of disease in the population that could be prevented if the modifiable risk factor (or exposure) was eliminated (Webb et al., 2017).

The aims for this present study are to:

1) Estimate the nature and extent of New Zealanders' exposure to nitrate in drinking water.

2) Estimate the number of colorectal cancers attributable to nitrate contamination of drinking water.

3) Estimate the potential health costs associated with excess nitrate concentrations in drinking water.

\section{Methods}

\subsection{Nitrate contamination dataset}

Data requests for current and historical nitrate data, supply characteristics and spatial files for supply boundaries were sent to the 66 District Councils in January 2020. Most District Councils treated the data request as an Official Information Act (OIA) Request under the Local Government Official Information and Meetings Act 1987, which requires the District Council to provide an official response within 20working days. Due to privacy restrictions, contact details for private non-District Council drinking water suppliers are not publicly available and could not be provided by the MoH for this study. The MoH Drinking Water Team invited 119 private drinking water suppliers (out of a total of 319) to participate in the study Drinking water nitrate data was requested from the private suppliers that agreed to be contacted for the study.

In March 2020, we requested nitrate data from Regional Councils (responsible for environmental monitoring), for bores that have been previously identified as being for domestic or community water supplies. Regional Councils are responsible for the management of natural and physical resources of a region, including source water for drinking water supplies (Ministry for the Environment, 2021). In addition, water samples were collected by one of the authors (JR) and analysed for nitrate from 20 unregistered supplies in the Southland District in December 2020.

\subsection{Colorectal cancer dataset}

Colorectal cancer incidence and mortality data for the year 2013 were retrieved from the Ministry of Health reporting series Cancer Registrations and Deaths (Ministry of Health, 2016). More recent data on CRC deaths are not freely available but there has been limited variability in CRC cases between 2013 (3075 cases) and 2018 (3189 cases). In 2013, there were 3075 new CRC cases and 1252 CRC deaths.

\subsection{Calculating nitrate exposure}

The current nitrate concentration for each registered water supply was calculated based on the average of 2018-2020 results using the nitrate data collected from the registered water supplies. Where a supplier did not have any results from the 2018-2020 period, the most recent result was used in the database. Nitrate samples from the reticulation or water treatment plant were used in preference to raw source water samples, where available. Where water is supplied from multiple sources with differing nitrate levels the nitrate level for the supply was 
calculated as a weighted average based on the proportional contribution of each source (when known).

In NZ, District Health Boards (DHBs, $\mathrm{n}=20$ ) are organisations responsible for providing or funding the provision of health services in their district (Ministry of Health, 2021). We calculated the population-weighted average exposure for each DHB and for the NZ population.

Exposure to nitrate in drinking water for those served by unregistered supplies was estimated based on the nitrate data collected from sampling unregistered supplies in one region and from the data provided from the Regional Councils in five other regions. The nitrate levels for the water sources in the Regional Council supplied data were calculated based on the average of the 2018 to 2020 results for each source. The nitrate levels for the unregistered water supplies sampled by the researcher were calculated based on the average of the results of the analyses for each supply.

To establish the average exposure on unregistered supplies for NZ and for each DHB we followed the same process as for registered supplies. However, the average exposure was multiplied by 0.75 to account for the estimated $25 \%$ of people relying on rainwater in these supplies as reported by the Institute of Environmental Science and Research (ESR) Data (ESR, 2019), the only data source available on the distribution of water source types (rainwater versus ground or surface water) for unregistered supplies.

\subsection{Statistical analysis}

To calculate the PAF for nitrate attributable CRC in NZ, we first created an effective risk ratio by multiplying the average exposure by the relative risk from Temkin's meta-analysis (average nitrate concentration $\mathrm{x}$ 0.04). This effective risk ratio was used in the standard population attributable fraction formula below in place of the relative risk (RR):

\section{$\boldsymbol{P A F}=\boldsymbol{P e}(\boldsymbol{R R}-1) /[\boldsymbol{P e}(\boldsymbol{R R}-1)+1] \times 100 \%$}

where:

$P A F$ is the population attributable fraction.

$\boldsymbol{P} \boldsymbol{e}$ is the prevalence of exposure.

$\boldsymbol{R} \boldsymbol{R}$ is the relative risk.

Because we calculated an effective risk ratio based on the average exposure, the prevalence of the risk factor was $100 \%$. Confidence intervals were calculated by running additional PAF analyses using the lower and upper confidence intervals from the Temkin meta-analysis $(1.01,1.07)$

\subsection{Direct and indirect costs of colorectal cancer in New Zealand}

To estimate the economic burden of nitrate contamination in drinking water we used available estimates of the direct and indirect costs of each CRC case. The economic cost of direct medical treatment for CRC in NZ is estimated to be 31,000 USD per case (Blakely et al., 2015). The indirect costs of each healthy year of life lost is estimated at 50,000 USD (Temkin et al., 2019). There is an estimated eight years of healthy life lost per diagnosed CRC case in NZ (Ministry of Health, 2013). Thus, the estimated indirect cost of each CRC case is 400,000
USD (e.g. $8 \times 50,000$ ). In total, we estimated the cost of each additional CRC case costs around 431,000 USD $(400,000+\$ 31,000)$.

\section{Results}

\subsection{Nitrate database completeness by supply type}

In total, we collated nitrate data on an estimated $85 \%$ of the NZ population (Table 1). The majority of the data come from large water suppliers (3.4 million, 73\%) who supply more than 10,000 people, while supplies with less than 25 people service around $13 \%$ of the population. The data coverage increases with the size of the water supplier from $0.4 \%$ for under 25 people to $100 \%$ for suppliers serving greater than 10,000 people. It is likely people on unregistered supplies are the most at-risk of nitrate contamination due to their typically rural residence being closer proximity to sources of nitrate leaching and because their water supply does not have the same regulatory monitoring that is carried out by registered water suppliers.

\subsection{Exposure to nitrate in drinking water in New Zealand}

The number of people in NZ exposed to nitrate at different thresholds is shown in Fig. 1. Among those on registered supplies, more than $65 \%$ of the population were exposed to less than $0.5 \mathrm{mg} / \mathrm{L}$ and an additional $10 \%$ less than $1 \mathrm{mg} / \mathrm{L}$. Around 6\% were exposed to between 1 and $2 \mathrm{mg} /$ $\mathrm{L}$, while $2.5 \%$ were exposed to greater than $2 \mathrm{mg} / \mathrm{L}$. Approximately 4400 people $(0.1 \%$ of the population) were exposed to greater than $50 \%$ of the MAV (5.7 mg/L). The numbers of people for whom there are no available nitrate data in the database are also shown, separated into those served by registered supplies $(\mathrm{n}=126,627)$ and those served by unregistered supplies $(n=603,566)$. In total, 410,292 people were exposed to greater than $1 \mathrm{mg} / \mathrm{L}$ while 730,193 have an unknown level of exposure.

\subsection{Estimating nitrate exposure in unregistered supplies}

The average nitrate level recorded across the 371 unregistered supplies was $5.04 \mathrm{mg} / \mathrm{L}$ (range 0.01-26.00, SD $5.08 \mathrm{mg} / \mathrm{L}$ ). We calculated the population-weighted average exposure for this population and assumed that this was representative of national exposures for people on unregistered supplies. We then multiplied this estimate by 0.75 to account for the estimated $25 \%$ of people on rainwater (ESR, 2019). Thus, we used $2.76 \mathrm{mg} / \mathrm{L}$ as our estimate for the average exposure of people on unregistered supplies.

\subsection{Population attributable fraction of colorectal cancer from nitrate in New Zealand drinking water}

Cancer registry data show that there were 3075 cases of CRC and 1252 deaths from CRC in NZ in 2013. We calculated that the average nitrate exposure for New Zealanders on a registered water supply $(84 \%$ of the total population) was $0.49 \mathrm{mg} / \mathrm{L}$ (Table 2). We estimated that the population attributable fraction from this exposure is $1.91 \%(95 \% \mathrm{CI}$ 0.49 to 3.30 ), amounting to 50 CRC cases (95\%CI 14.9 to 101.6 ) and 20 CRC deaths (95\%CI 5.1 to 34.9 ) at a cost of 21.3 million USD (95\%CI 6.4

Table 1

Nitrate data compiled in the nitrate database on New Zealand drinking water by water supply size category.

\begin{tabular}{|c|c|c|c|c|c|c|c|}
\hline \multicolumn{8}{|c|}{ Drinking water supply category and size (number of people) } \\
\hline & $\begin{array}{l}\text { Unregistered } \\
(<25)\end{array}$ & $\begin{array}{l}\text { Neighbourhood } \\
(25-100)\end{array}$ & $\begin{array}{l}\text { Small } \\
(101-500)\end{array}$ & $\begin{array}{l}\text { Minor } \\
(501-5000)\end{array}$ & $\begin{array}{l}\text { Medium } \\
(5001-10,000)\end{array}$ & $\begin{array}{l}\text { Large } \\
(>10,000)\end{array}$ & Total \\
\hline Total with data & 2593 & 1988 & 34,055 & 303,796 & 158,053 & $3,471,670$ & $3,972,155$ \\
\hline No data & 600,973 & 8863 & 23,187 & 73,664 & 21,203 & 0 & 727,890 \\
\hline Population & 603,566 & 10,851 & 57,242 & 377,460 & 179,256 & $3,434,362$ & $4,662,737$ \\
\hline$\%$ data coverage & $0.4 \%$ & $18 \%$ & $59 \%$ & $80 \%$ & $88 \%$ & $100 \%$ & $85 \%$ \\
\hline
\end{tabular}




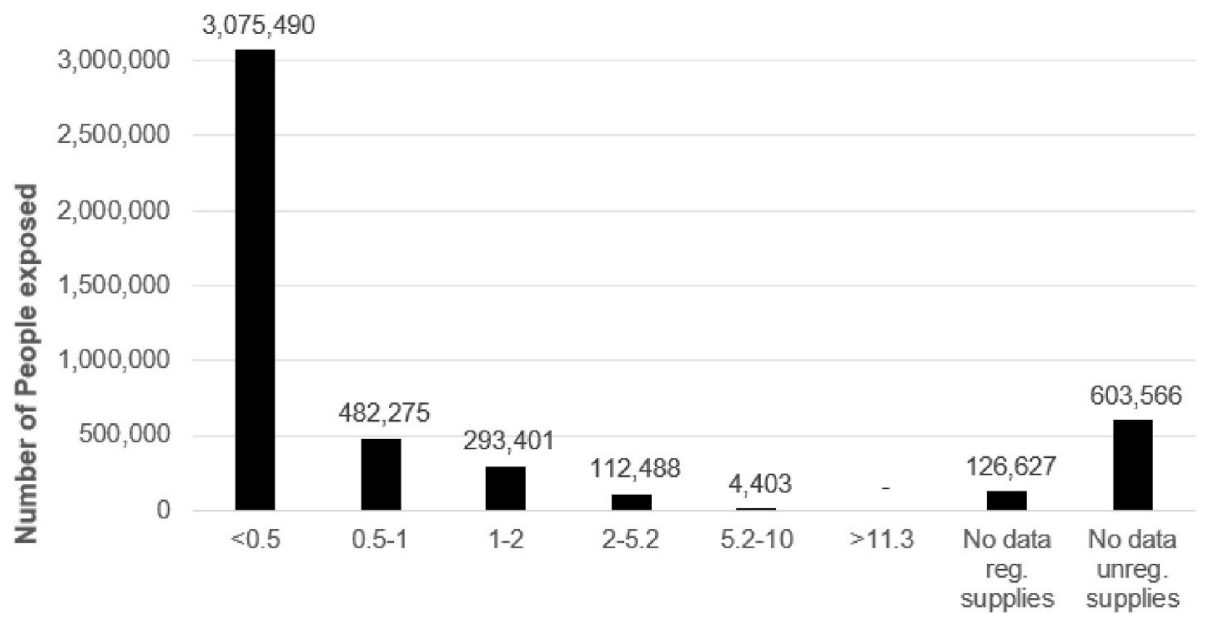

Nitrate Concentration Range (as mg/L NO3-N)

Fig. 1. Distribution of nitrate exposure from drinking water in New Zealand presented in $\mathrm{NO}_{3}-\mathrm{N} \mathrm{mg} / \mathrm{L}$.

Table 2

Estimated population attributable fraction of colorectal cancer from nitrate contamination of drinking water in New Zealand.

\begin{tabular}{|c|c|c|c|c|c|c|c|}
\hline Supply type & $\begin{array}{l}\text { NZ Population } \\
(\%)\end{array}$ & $\begin{array}{l}\text { Nitrate concentration mg/L } \\
\text { NO3-N }\end{array}$ & $\begin{array}{l}\text { Effective risk } \\
\text { ratio }\end{array}$ & $\mathrm{PAF}$ as $\%$ & $\begin{array}{l}\text { Attributable } \\
\text { cases }\end{array}$ & $\begin{array}{l}\text { Attributable } \\
\text { deaths }\end{array}$ & $\begin{array}{l}\text { Economic costs per year } \\
\text { (million USD) }\end{array}$ \\
\hline $\begin{array}{r}\text { Registered } \\
\text { supplies }\end{array}$ & 84.4 & 0.49 & $\begin{array}{l}1.020(1.005 \\
1.034)\end{array}$ & $\begin{array}{l}1.91(0.49, \\
3.30)\end{array}$ & $\begin{array}{l}49.7(14.9, \\
101.6)\end{array}$ & $20.2(5.1,34.9)$ & $21.3(6.4,43.5)$ \\
\hline All supplies & 100 & 0.84 & $\begin{array}{l}1.034 \text { (1.008, } \\
1.059)\end{array}$ & $\begin{array}{l}3.26(0.84, \\
5.57)\end{array}$ & $\begin{array}{l}100.3(25.7 \\
171.3)\end{array}$ & $40.8(10.5,69.7)$ & $43.2(10.9,73.4)$ \\
\hline
\end{tabular}

to 43.5) per year. These estimates double when we account for the potential burden from the $15.6 \%$ of New Zealanders who are currently supplied by unregistered suppliers and are at most risk of contaminated drinking water. When registered and unregistered supply estimates are combined, we estimated nitrate contamination contributes to 100.3 attributable CRC cases (95\%CI 25.7 to 171.3 ) and 40.8 CRC deaths (95\% CI $10.5,69.7)$ at the cost of 43.2 million USD (95\%CI 10.9 to 73.4$)$ per year.

\section{Discussion}

The majority of people in NZ are on water supplies with low levels of nitrate contamination (less than $0.5 \mathrm{mg} / \mathrm{L}$ ). In total, 410,292 people supplied by registered water suppliers ( $9 \%$ ) had nitrate exposure greater than that observed by Schullehner et al. (2018) as a CRC risk (1 mg/L). However, there are a large proportion of people on unregistered supplies $(600,000$ or $\sim 15 \%)$ who are at the greatest risk of exposure to nitrate in drinking water, and data were missing from an additional 130,000 people. Thus, while some areas appear to have low levels of nitrate contamination, this may be due to unaccounted unregistered supplies or registered supplies with missing data. When accounting for unregistered supplies we estimate a PAF of $3.26 \%$, resulting in 100 nitrate-attributable CRC cases, 41 deaths and costs of 43.2 million USD each year.

This study found NZ generally has lower exposure to drinking water nitrate than European countries or the US. At the lower end, 14.4\% (including unregistered supplies) of New Zealanders are exposed to greater than $1 \mathrm{mg} / \mathrm{L}$ in drinking water, compared to $28.9 \%$ in the United States (Temkin et al., 2019). At the higher end, only $2.2 \%$ of the NZ population is exposed to greater than $5 \mathrm{mg} / \mathrm{L}$ in drinking water, compared to an estimated $6.5 \%$ of the population of 12 European Union member states (van Grinsven et al., 2010). Intensive agricultural activities have been practised for much longer in Europe and the US than in $\mathrm{NZ}$, and this history may be why nitrate contamination is less in NZ. However, increases in pollution since 1990 in NZ are starting to move through ground water systems, as reflected in ground water monitoring conducted by regional councils (not necessarily drinking water supplies) which has shown nitrate levels at $62 \%$ of sites have increased since 2005 (Statistics New Zealand, 2019a). Increases are likely due to major scaling up of dairy farming which has seen a $50 \%$ increase in stocking numbers since 1990, with an estimated 130 million kilograms $(\mathrm{kg})$ of nitrate leached in 2017 alone (a 73\% increase from 1990 levels) (Statistics New Zealand, 2019b).

\subsection{Nitrate-attributable colorectal cancer}

We estimated that 50 CRC cases and 21 deaths (1.91\%) were attributable to nitrate contamination in people on registered supplies in $\mathrm{NZ}$, and 100 cases and 41 deaths (3.26\%) in the total population when accounting for people on unregistered supplies. These estimates sit on the lower end of Temkin's estimates of $4 \%$ (95\%CI 1-8\%). We applied Temkin's dose-response effective rate ratio to account for the potential impact of nitrate exposure, even at low levels. This calculation assumes that there is a linear, no threshold effect of nitrate exposure on CRC risk. We acknowledge there is still debate over whether there is a threshold effect of nitrate exposure. To explore the impact of a threshold effect, we conducted PAF analyses applying rate ratios from both Schullehner et al. (2018) (0.87-2.03 mg/L, RR 1.11; > 2.04, RR 1.15) and Espejo-Herrera et al. (2016) ( $>1.56$, RR 1.49) as the threshold (Supplementary Table 1). In these analyses, the estimated PAFs were $2.14 \%$ and $5.60 \%$ with an estimated 69 and 180 CRC cases, respectively. Consequently, our linear effect estimate sits in between these two threshold effect estimates.

Exposure to nitrate in drinking water may have a similar significance to the established risk factors of high consumption of red meat, physical inactivity, processed meat, alcohol and smoking, that have estimated PAFs between 2.5 and $4.8 \%$ in NZ (Richardson et al., 2016). Our PAF estimate for nitrate-attributable CRC is below some of these other risk factors but it is of as much, if not more, concern for various reasons. Unlike other risk factors of CRC such as alcohol or tobacco, access to clean water is a fundamental human right under the United Nations 
Resolution 64/292 (United Nations General Assembly, 2010) and is enshrined as one of the 17 United Nations' Sustainable Development Goals (United Nations General Assembly, 2015). In NZ, water is a taonga (treasure), failing to protect water is a breach of Te Tiriti o Waitangi (the Treaty of Waitangi), NZ's constitutional document between the Crown and Māori (New Zealand's indigenous population) (Stewart-Harawira, 2020). Failings in water management have been and continue to be the subject of multiple claims to the Waitangi Tribunal, the court established by the NZ Government to hear claims by Māori iwi (tribes) and hapu (sub-tribes) against Crown for breaches of Te Tiriti o Waitangi.

\subsection{Costs of nitrate contamination and remediation}

The direct and indirect costs of nitrate-attributable cancer in NZ was estimated at 43.2 million USD per year ( 431,000 per case). A European economic analysis estimated that each $\mathrm{kg}$ of nitrate leached had a health cost due to CRC of 0.90 USD (van Grinsven et al., 2010). Translated to $\mathrm{NZ}$, the health cost $=$ from nitrate-attributable CRC would be 118 million USD (130 million *0.90) from dairy farm leaching alone (Statistics New Zealand, 2019b). Van Grinsven's estimates may be an underestimate given they only consider health effects at exposure greater than $5.5 \mathrm{mg} / \mathrm{L}$ despite the majority of the population burden of disease likely occurring below this threshold.

Once a water supply is contaminated with nitrate it is very difficult and costly to remove. The cost of removal depends on the system used, the size of the water supply and the extent of the contamination and required removal. The most commonly used and cost effective is ionexchange where nitrate ion is substituted for another ion (Schechinger and Cox, 2018). A recent cost estimate for ion-exchange treatment system for one NZ city water supply was between 597 million and 1547 million USD (Birdling, 2020). Even once water is treated, there is the issue of removing the waste brine of concentrated nitrate.

\subsection{Water reforms in New Zealand}

In NZ, there are major policy and structural changes that provide an opportunity for meaningful action on drinking water. The first major opportunity is through the establishment of an independent water regulator, Taumata Arowai. Taumata Arowai may have the potential authority to review, implement and enforce drinking water standards in NZ (New Zealand Parliament 2021), including establishing a nitrate limit for chronic health conditions. As such, the new water regulatory could set a lower nitrate limit for drinking water, upon appropriate health advice. Some Regional Councils are already targeting limits much lower than the current $11.3 \mathrm{mg} / \mathrm{L}$ to improve their drinking water assets (Environment Canterbury is proposing setting limits of $5.65 \mathrm{mg} / \mathrm{L}$ ). Taumata Arowai will also require smaller suppliers to register and regularly monitor their water supplies resulting in a more comprehensive national database of water contaminants. Finally, Taumata Arowai may require all persons who perform or exercise functions, powers, and duties under the legislation to give effect to Te Mana o te Wai (New Zealand Parliament 2021). Te Mana o te Wai is an approach to water management that recognises the fundamental relationship between the health of the water and wider societal outcomes, placing the health of the water before all else (Te Aho, 2019). The Water Services Bill operationalised Te Mana o te Wai through its prevention focused risk management approach that requires suppliers to have a Water Safety Plan and Water Source Protection Plan. Drinking water suppliers will be required to monitor the source water quality, in addition to the treated water, to uphold the health of source water and action Te Mana o te Wai.

There are also opportunities to improve drinking water and reduce nitrate contamination via freshwater reforms. New Zealand has a National Policy Statement for Freshwater Management (NPS-FM) which was enacted in 2011 that sets national bottom lines for median nitrate of $6.7 \mathrm{mg} / \mathrm{L}$ (2014) and $2.4 \mathrm{mg} / \mathrm{L}$ (2020) (New Zealand Government 2014, 2020). These limits are still higher than the $1 \mathrm{mg} / \mathrm{L}$ recommended by the
Government Water Taskforce and were implemented two decades late (the NPS is part of the Resource Management Act 1991) (Joy and Canning, 2020). In 2020, the freshwater reform package was announced which included a nitrogen fertilizer cap of $190 \mathrm{~kg} \mathrm{~N} / \mathrm{ha} / \mathrm{yr}$ in 2021, stock exclusion from waterways wider than $1 \mathrm{~m}$ from 2023 and limits on high-risk farming practices such as winter grazing. Some of the reforms are still being considered (such as nitrate bottom lines), while freshwater advocates are pushing for tougher restrictions (Dreaver, 2020). This study provides support for more stringent water reforms and demonstrates the potential health loss from relaxed legislation.

\subsection{Strengths and limitations}

There are a number of strengths with this study. We achieved a relatively high coverage of the NZ population in our nitrate database, compiling data from individual suppliers from all over the country. Our study gives the first comprehensive view of the distribution of nitrate contamination in drinking water in NZ and identified where gaps exist. Further, our national estimate adds to the limited global evidence of national-level nitrate exposure estimates. Another strength was the use of historical data and sampled data from Regional Councils to estimate the potential exposure of people on unregistered supplies. Compared to other studies (De Roos et al., 2003; Espejo-Herrera et al., 2016), our exposure estimates for unregistered supplies is low - but as noted earlier, the effects of NZ dairy intensification may only just be starting to influence groundwater quality. Lastly, we were able to estimate the potential nitrate-attributable CRC rates in NZ using three methods (Espejo-Herrera et al., 2016; Schullehner et al., 2018; Temkin et al., 2019), that account for both a linear and threshold effect of nitrate exposure on CRC.

Population-based studies in Denmark, USA, Spain and Italy have reported an increased risk of CRC from nitrate concentrations well below the regulatory guidelines (De Roos et al., 2003; Espejo-Herrera et al., 2016; Schullehner et al., 2018; Weyer et al., 2001). Some studies have produced mixed results with null findings or non-linear relationships between water-based nitrate and CRC (De Roos et al., 2003; Jones et al., 2019; McElroy et al., 2008; Weyer et al., 2001). These studies were conducted on specific populations such as older women aged 55-69 (Jones et al., 2019; Weyer et al., 2001) or rural populations (McElroy et al., 2008) limiting their generalisability. These studies have also had small samples when split across multiple exposure groups, with some trials having as few as five cases in the top exposure bracket (McElroy et al., 2008) and as few as 30 cases overall.

The two most methodologically rigorous studies conducted to date on nitrate contamination and CRC are Schullehner et al. (2018) and Espejo-Herrera et al. (2016). Schullehner et al. (2018) was a nation-wide, cohort study across the Danish population ( $\mathrm{n}=3$ million, with 44 million observed person-years). Annual average drinking water nitrate concentrations were assigned to each individual in the study by linking their residential history to a national nitrate database for public and private water supplies that dates back to 1978 . The authors found an $11 \%$ increased risk of CRC for individuals exposed to average drinking water nitrate concentrations above $0.87 \mathrm{mg} / \mathrm{L}$ compared to individuals with less than $0.30 \mathrm{mg} / \mathrm{L}$. The study had a large sample, with a robust exposure measurement and adjusted for key confounders (age, sex, socio-economic status). Note, that in Denmark, other major risk factors for CRC such as alcohol, smoking and diet are socially patterned so were indirectly adjusted for with the included variables. Espejo-Herrera (2016) was a case-control study with 1869 CRC cases matched with 3530 controls in Spain and Italy. Nitrate levels were assigned to each individual based on the participant's residential history, nitrate data was collected from public and private supplies and authors adjusted for participants reported daily water intake. Long-term exposure to nitrate-nitrogen concentrations above $1.61 \mathrm{mg} / \mathrm{L}$ was associated with $49 \%$ increased CRC risk compared to individuals with concentrations less than $0.80 \mathrm{mg} / \mathrm{L}$ (reference group). Key confounders (sex, age, SES, 
physical activity, smoking and family history of CRC) were adjusted for in analyses. A recent meta-analysis did not consider a safe lower level, but reported a $4 \%$ increase in CRC risk per $\mathrm{mg} / \mathrm{L}$ increase in nitrate concentrations (OR 1.04, 95\%CI 1.01, 1.07) (Temkin et al., 2019).The current study did not aim to establish causality but relies on the previous epidemiological evidence showing an association between nitrate and CRC and as such it does not directly assess the relationship between individual exposure to nitrate and CRC. While we used a sub-sample of unregistered supplies, there is a major gap in our knowledge with those most at risk being most likely to not have nitrate exposure data. Our exposure estimate for unregistered supplies is a preliminary estimate that is likely conservative in comparison to other studies (De Roos et al., 2003; Espejo-Herrera et al., 2016). Further, applying an exposure estimate uniformly across the country does not account for the inter-regional differences in the factors like soil type and rainfall that influence nitrate leaching. As such, drawing conclusions at a regional level based on these extrapolations may misrepresent the potential risk in some areas.

Further surveillance and research could improve the robustness of disease burden estimates described in this paper. The most urgent need is for comprehensive testing data on nitrate levels and water sources used by unregistered supplies. NZ may also be able to add to the small international evidence base on the relationship between nitrate levels and risk of CRC. One limitation of conducting such research in this country is that nitrate levels and exposures have been relatively low historically, though are rapidly increasing at present, so it may be hard to measure dose-response relationships in this setting.

\section{Conclusion}

Most New Zealanders are exposed to relatively low levels of nitrate but some are exposed to high levels (eg 14\% exposed to water supplies with more than $1 \mathrm{mg} / \mathrm{L} \mathrm{NO}_{3}-\mathrm{N}$ ), and many take water from supplies that are not monitored for nitrate. Consequently, we estimate that about 3\% of CRC cases in NZ may be attributed to nitrate contamination of drinking water. Recent epidemiological studies of the association between cancer and nitrate ingestion from drinking water reinforce the urgency to review the drinking water standards in NZ. There are opportunities in this country, with the establishment of a new water regulator, operationalisation of Te Mana o te Wai, comprehensive water services legislation and freshwater reforms, for transformative change of drinking water management.

\section{Declaration of competing interest}

The authors declare that they have no known competing financial interests or personal relationships that could have appeared to influence the work reported in this paper.

\section{Acknowledgments}

This work would not have been possible without the significant contribution of the drinking water suppliers who provided nitrate data and supply information for their water supplies and the Regional Councils that provided nitrate data and information on the use of bores for domestic consumption. Thank you also to ESR, Environment Canterbury and the $\mathrm{MoH}$ for providing data and advice throughout the project. We also acknowledge those private water suppliers that provided data to the project. No direct funding was acquired for this research. TC is funded by a donation from the GAMA foundation.

\section{Appendix A. Supplementary data}

Supplementary data to this article can be found online at https://doi. org/10.1016/j.envres.2021.112322.

\section{References}

Almasri, M.N., 2007. Nitrate contamination of groundwater: a conceptual management framework. Environ. Impact Assess. Rev. 27, 220-242. https://doi.org/10.1016/j. eiar.2006.11.002.

Birdling, G., 2020. Evidence in Chief of Greg Birdling for Christchurch City Council, Land and Water Regional Plan Change 7 Hearing Dated 17 July 2020. Online. https://api. ecan.govt.nz/TrimPublicAPI/documents/download/3909177. (Accessed 17 February 2021).

Blakely, T., Atkinson, J., Kvizhinadze, G., Wilson, N., Davies, A., Clarke, P., 2015. Patterns of cancer care costs in a country with detailed individual data. Med. Care 53. https://doi.org/10.1097/MLR.0000000000000330, 302-209.

Bray, F., Ferlay, J., Soerjomataram, I., Siegel, R.L., Torre, L.A., Jemal, A., 2018. Global cancer statistics 2018: GLOBOCAN estimates of incidence and mortality worldwide for 36 cancers in 185 countries. CA A Cancer J. Clin. 68, 394-424. https://doi.org/ 10.3322/caac. 21492 .

De Roos, A.J., Ward, M.H., Lynch, C.F., Cantor, K.P., 2003. Nitrate in public water supplies and the risk of colon and rectum cancers. Epidemiology 14, 640-649.

Dreaver, C., 2020. Government pushes ahead with landmark freshwater reform. Online: Radio New Zealand. https://www.rnz.co.nz/news/political/417788/government -pushes-ahead-with-landmark-freshwater-reform. (Accessed 18 February 2021).

Espejo-Herrera, N., Gràcia-Lavedan, E., Boldo, E., Aragonés, N., Pérez-Gómez, B., Pollán, M., et al., 2016. Colorectal cancer risk and nitrate exposure through drinking water and diet. Int. J. Cancer 139, 334-346. https://doi.org/10.1002/ijc.30083.

ESR, 2019. Archived Dataset from Ministry of Health's Priority Two Chemical Determinands Identification Programme 1995-2004. Christchurch (NZL). Institute of Environmental Science and Research.

ESR, 2020. Drinking Water for New Zealand. Institute of Environmental Science and Research, online. https://www.drinkingwater.esr.cri.nz/default.asp. (Accessed 10 April 2020).

Favoriti, P., Carbone, G., Greco, M., Pirozzi, F., Pirozzi, R.E.M., Corcione, F., 2016. Worldwide burden of colorectal cancer: a review. Update Surg. 68, 7-11. https:// doi.org/10.1007/s13304-016-0359-y.

Gurjao, C., Zhong, R., Haruki, K., Li, Y.Y., Spurr, L.F., Lee-Six, H., et al., 2021. Discovery and features of an alkylating signature in colorectal cancer. Cancer Discov. https:// doi.org/10.1158/2159-8290.CD-20-1656.

Hughes, R., Cross, A.J., Pollock, J.R.A., Bingham, S., 2001. Dose-dependent effect of dietary meat on endogenous colonic N-nitrosation. Carcinogenesis 22, 199-202. https://doi.org/10.1093/carcin/22.1.199.

International Agency for Research on Cancer, 2010. Ingested nitrate and nitrite, and cyanobacterial peptide toxins. (IARC monographs on the evaluation of carcinogenic risks to humans). Lyon (FRA). https://publications.iarc.fr/publications/media/do wnload/2867/c9f9c85d6dd616d774bdbbe67bae77bddeb1b4de.pdf. (Accessed 25 February 2021).

Johnson, C.M., Wei, C., Ensor, J.E., Smolenski, D.J., Amos, C.I., Levin, B., et al., 2013. Meta-analyses of colorectal cancer risk factors. Cancer Causes Control 24, 1207-1222. https://doi.org/10.1007/s10552-013-0201-5.

Jones, R.R., DellaValle, C.T., Weyer, P.J., Robien, K., Cantor, K.P., Krasner, S., et al., 2019. Ingested nitrate, disinfection by-products, and risk of colon and rectal cancers in the Iowa Women's Health Study cohort. Environ. Int. 126, 242-251. https://doi. org/10.1016/j.envint.2019.02.010.

Joy, M.K., Canning, A.D., 2020. Shifting baselines and political expediency in New Zealand's freshwater management. Mar. Freshw. Res. https://doi.org/10.1071/ MF20210.

McElroy, J.A., Trentham-Dietz, A., Gangnon, R.E., Hampton, J.M., Bersch, A.J., Kanarek, M.S., et al., 2008. Nitrogen-nitrate exposure from drinking water and colorectal cancer risk for rural women in Wisconsin, USA. J. Water Health 6, 399-409. https://doi.org/10.2166/wh.2008.048.

Ministry for the Environment, 2021. Roles and Responsibilities of Local Government under the RMA. Online:Ministry for the Environment. https://www.mfe.govt. $\mathrm{nz} / \mathrm{rma} /$ about-rma/roles-and-responsibilities/local-government. (Accessed 12 March 2020).

Ministry for the Environment \& Stats NZ, 2019. New Zealand's Environmental Reporting Series: Environment Aotearoa 2019. Wellington (NZL). https://www.mfe.govt.nz/sit es/default/files/media/Environmental\%20reporting/environment\%20-aotearoa-20 19.pdf. (Accessed 25 February 2021).

Ministry of Health, 2013. Health Loss in New Zealand: A Report from the New Zealand Burden of Diseases, Injuries and Risk Factors Study, 2006-2016. Wellington (NZL): Ministry of Health. https://www.moh.govt.nz/notebook/nbbooks.nsf/0/F85C39 E4495B9684CC257BD3006F6299/\$file/health-loss-in-new-zealand-final.pdf. (Accessed 25 February 2021).

Ministry of Health, 2016. Cancer New Registrations and Deaths 2013. Wellington (NZL): Ministry of Health. https://www.health.govt.nz/system/files/documents/publicatio ns/cancer-new-registrations-deaths-2013-nov16.pdf. (Accessed 19 April 2021).

Ministry of Health, 2020. Annual Report on Drinking-Water Quality. Wellington (NZL): Ministry of Health. https://www.health.govt.nz/system/files/documents/publicati ons/annual-report-drinking-water-quality-2018-2019-25june2020.pdf. (Accessed 25 February 2021).

Ministry of Health, 2021. District health boards. Online:Ministry of Health. https ://www.health.govt.nz/new-zealand-health-system/key-health-sector-organisatio ns-and-people/district-health-boards. (Accessed 11 February 2021).

Morgenstern, U., Daughney, C.J., 2012. Groundwater age for identification of baseline groundwater quality and impacts of land-use intensification - the National Groundwater Monitoring Programme of New Zealand. J. Hydrol. 456-457, 79-93. https://doi.org/10.1016/j.jhydrol.2012.06.010. 
New Zealand Government, 2014. National Policy Statement for Freshwater Management 2014. Wellington (NZL):New Zealand Government. https://www.mfe.govt.nz/site s/default/files/media/Fresh\%20water/nps-freshwater-ameneded-2017_0.pdf. (Accessed 17 February 2021).

New Zealand Government, 2020. National Policy Statement for Freshwater Management 2020. Wellington (NZL):New Zealand Government. https://www.mfe.govt.nz/site $\mathrm{s} /$ default/files/media/Fresh\%20water/national-policy-statement-for-freshwatermanagement-2020.pdf. (Accessed 17 February 2021).

New Zealand Parliament, 2021. Water Services Bill. Wellington (NZL):New Zealand Parliament. https://www.parliament.nz/en/pb/bills-and-laws/bills-proposed-laws/ document/BILL_99655/water-services-bill. (Accessed 11 February 2021).

Parliamentary Commissioner for the Environment, 2013. Water Quality in New Zealand: Land Use and Nutrient Pollution. Parliamentary Commissioner for the Environment, Wellington (NZL)

Purcell, R.V., Pearson, J., Aitchison, A., Dixon, L., Frizelle, F.A., Keenan, J.I., 2017. Colonization with enterotoxigenic Bacteroides fragilis is associated with early-stage colorectal neoplasia. PLoS One 12, e0171602. https://doi.org/10.1371/journal. pone.0171602.

Richardson, A., Hayes, J., Frampton, C., Potter, J., 2016. Modifiable lifestyle factors that could reduce the incidence of colorectal cancer in New Zealand. NZ Med. J. 129 https://assets-global.website-files.com/5e332a62c703f653182faf47/5e332a62c70 3f6b1202fd059_Richardson\%20FINAL.pdf.

Rowland, I., Granli, T., Bøckman, O., Key, P., Massey, R., 1991. Endogenous Nnitrosation in man assessed by measurement of apparent total N-nitroso compounds in faeces. Carcinogenesis 12, 1395-1401.

Schechinger, A., Cox, C., 2018. America's Nitrate Habit Is Costly and Dangerous. Online. The Environmental Working Group. https://www.ewg.org/research/nitratecost/. (Accessed 16 March 2021).

Schullehner, J., Hansen, B., Thygesen, M., Pedersen, C.B., Sigsgaard, T., 2018. Nitrate in drinking water and colorectal cancer risk: a nationwide population-based cohort study. Int. J. Cancer 143, 73-79. https://doi.org/10.1002/ijc.31306.

Statistics New Zealand, 2019a. Groundwater Quality - Published April 2019. Online: Statistics New Zealand. https://www.stats.govt.nz/indicators/groundwater-quality -published-april-2019\#: : text=half\%20the\%20sites\%20had\%20absolute,of\%20the \%20five-year\%20median. (Accessed 15 February 2021).

Statistics New Zealand, 2019b. Nitrate leaching from livestock. online:Statistics New Zealand. https://www.stats.govt.nz/indicators/nitrate-leaching-from-livestock. (Accessed 16 February 2021).

Statistics New Zealand, 2020. Age and sex by ethnic group (grouped total responses), for the census usually resident population count, 2006, 2013, and 2018 Censuses (RC TA, SA2, DHB). Online:Statistics New Zealand. https://www.stats.govt.nz/topics/p opulation. (Accessed 8 March 2020). accessed.
Stewart-Harawira, M.W., 2020. Troubled waters: Maori values and ethics for freshwater management and New Zealand's fresh water crisis. WIREs Water 7, e1464. https:// doi.org/10.1002/wat2.1464.

Te Aho, L., 2019. Te Mana o te Wai: an indigenous perspective on rivers and river management. River Res. Appl. 35, 1615-1621. https://doi.org/10.1002/rra.3365.

Temkin, A., Evans, S., Manidis, T., Campbell, C., Naidenko, O.V., 2019. Exposure-based assessment and economic valuation of adverse birth outcomes and cancer risk due to nitrate in United States drinking water. Environ. Res. 176, 108442 https://doi.org/ 10.1016/j.envres.2019.04.009.

United Nations General Assembly, 2010. Resolution 64/292: the Human Right to Water and Sanitation. United Nations, Geneva (CHE). https://www.un.org/ga/search/view doc.asp?symbol=A/RES/64/292. (Accessed 17 February 2021).

United Nations General Assembly, 2015. Transforming Our World: the 2030 Agenda for Sustainable Development. United Nations, Geneva (CHE). https://sdgs.un.org/site s/default/files/publications/21252030\%20Agenda\%20for\%20Sustainable\%20De velopment $\% 20$ web.pdf. (Accessed 15 March 2021).

van Breda, S.G., Mathijs, K., Sági-Kiss, V., Kuhnle, G.G., Van der Veer, B., Jones, R.R. et al., 2019. Impact of high drinking water nitrate levels on the endogenous formation of apparent $\mathrm{N}$-nitroso compounds in combination with meat intake in healthy volunteers. Environ. Health 18, 87. https://doi.org/10.1186/s12940-0190525-z.

van Grinsven, H.J.M., Rabl, A., de Kok, T.M., 2010. Estimation of incidence and social cost of colon cancer due to nitrate in drinking water in the EU: a tentative costbenefit assessment. Environ. Health 9, 58. https://doi.org/10.1186/1476-069X-958.

Vogeler, I., Lucci, G., Shepherd, M., 2015. An assessment of the effects of fertilizer nitrogen management on nitrate leaching risk from grazed dairy pasture. J. Agric. Sci. 154, 407-424. https://doi.org/10.1017/S0021859615000295.

Ward, M.H., Jones, R.R., Brender, J.D., De Kok, T.M., Weyer, P.J., Nolan, B.T., et al., 2018. Drinking water nitrate and human health: an updated review. Int. J. Environ. Res. Publ. Health 15, 1557. https://doi.org/10.3390/ijerph15071557.

Webb, P., Bain, C., Page, A., 2017. Essential Epidemiology: an Introduction for Students and Health Professionals. Cambridge University Press.

Weyer, P.J., Cerhan, J.R., Kross, B.C., Hallberg, G.R., Kantamneni, J., Breuer, G., et al., 2001. Municipal drinking water nitrate level and cancer risk in older women: the Iowa Women's Health Study. Epidemiology 12, 327-338.

World Health Organization, 2017. In: Guidelines for Drinking-Water Quality: Fourth Edition Incorporating the First Addendum. Geneva (CHE). https://apps.who.int/iri s/bitstream/handle/10665/254637/9789241549950-eng.pdf;jsessionid=6 53DBF3E25683F182CA7C095E5F61A04? sequence=1. (Accessed 11 August 2020).

Zhu, Y., Wang, P.P., Zhao, J., Green, R., Sun, Z., Roebothan, B., et al., 2014. Dietary Nnitroso compounds and risk of colorectal cancer: a case-control study in Newfoundland and Labrador and Ontario, Canada. Br. J. Nutr. 111, 1109-1117. https://doi.org/10.1017/S0007114513003462. 